The Philosophical Quarterly Vol. 63, No. 250

ISSN oo3I-8094

\title{
THE INFORMATIONAL RICHNESS OF TESTIMONIAL GONTEXTS
}

\author{
By Tim KenYON
}

An influential idea in the epistemology of testimony is that people often acquire justified beliefs through testimony, in contexts too informationally poor for the justification to be evidential. This has been described as the Scarcity of Information Objection (SIO). It is an objection to the reductive thesis that the acceptance of testimony is justified by evidence of general kinds not unique to testimony. SIO hinges on examples intended to show clearly that testimonial justification arises in low-information contexts; I argue that the common examples show no such thing. There is a great deal of information available in testimonial contexts, including in the examples alleged to show otherwise - enough information to render SIO implausible. Purported SIO examples tend to give a wrong impression about the informational richness of testimonial contexts, I argue, due to the lack of detail in which they are presented.

\section{THE SCARGITY OF INFORMATION OBJEGTION}

I have no problem asking strangers for directions. I do it in my own city, and I do it when traveling abroad - sometimes with unfortunate results that seem to show a mismatch between other people's willingness to give directions and their grasp of the local geography. So I take myself to have a reasonably informed perspective on Jennifer Lackey's example of justified belief arising from testimony in a seemingly low-information situation.

[W] hen I ask a stranger on the street for directions to the Empire State Building, do I have enough information about her to justify my accepting her testimony that it is six blocks north? Or, traveling to London for the first time, do I have enough evidence about a random British newspaper to adequately justify the beliefs I acquire while reading it?

This, to my mind, is a very compelling objection to reductionism. ${ }^{1}$

${ }^{\mathrm{I}}$ J. Lackey, Learning from Words (Oxford UP, I990), p. I80. 
Momentarily I will give a brief accounting of how reductionism bears on the question at hand. First, though, what is the question at hand? The objection Lackey notes in the passage just quoted is one she calls the Scarcity of Information Objection (SIO). SIO consists in the claim that ' $[\mathrm{o}]$ rdinary epistemic agents simply do not have enough information to acquire positive reasons strong enough to justify accepting most of the testimony that is intuitively justified or warranted' (p. I8o).

This way of framing SIO thus amounts to a fairly sweeping view about the nature of most of our beliefs from testimony (BFT). ${ }^{2}$ The focus narrows considerably, though, when we look at the examples offered as motivating SIO in much of the literature. These are cases of the default acceptance of testimony, by which I mean the process of automatic, fast and implicit acceptance that characterises much of our BFT acquisition. SIO examples are taken to show that justified BFTs are acquired in contexts of communication that are too informationally impoverished to evidentially justify the acceptance. If I form and hold a justified BFT in a context, but I don't have enough evidence in that context to justify it, then the justification for my BFT can't be evidential in the relevant respect. ${ }^{3}$

I don't think the SIO examples show this, though. Indeed, I doubt that there exists any pairing of a testimonial context $\mathrm{C}$ and a testimonial belief $\mathrm{B}$, such that $\mathrm{G}$ is clearly too informationally impoverished to provide reasons sufficient to justify $\mathrm{B}$, even though $\mathrm{B}$ is clearly justified in that context. I will argue this primarily by emphasising the amount and kinds of information at our disposal in testimonial contexts - factors often mentioned in the epistemology of testimony, but, I believe, too rarely appreciated in their significance and detail when examples are constructed and

${ }^{2}$ Others in this literature, including Lackey, sometimes allude to testimony-based belief as the phenomenon of interest in the epistemology of testimony. TBB is often defined as presupposing a noninferential view of belief fixation. See, for example, R. Audi, 'Testimony, Credulity, and Veracity', in J. Lackey and E. Sosa (eds.), The Epistemology of Testimony (Oxford UP, 2006), pp. 25-49; and D. Pritchard, 'The Epistemology of Testimony', Philosophical Issues, I4 (2004), pp. 326-48. I use 'BFT' to encompass the general phenomenon of encountering testimony, understanding it, and coming to believe its content. It is defined without prejudice as to whether the phenomenon includes belief-dependent cases of belief arising from testimony. For the argument against TBB and in favour of BFT, see T. Kenyon, 'Noninferentialism and Testimonial Belief Fixation' Episteme, Io.I (forthcoming).

${ }^{3}$ Some writers distinguish between a belief's being doxastically justified and a person's being justified in forming or holding a belief. See P. Faulkner, 'The Social Character of Testimonial Knowledge', The Fournal of Philosophy, 97, (2000), pp. 58I-6or; and J. Pryor, 'There Is Immediate Justification', in M. Steup and E. Sosa (eds.), Contemporary Debates in Epistemology (Oxford: Blackwell, 2005), pp. I8I-20I. As the opening quote from Lackey suggests, this distinction is not always employed in characterising SIO. For current purposes I will not use it. 
analysed. On four main grounds, I think we have a very great deal of relevant and potentially justificatory information in testimonial contexts.

The first two grounds are closely related. (I) Testimonial contexts may well be temporally sprawling creatures; lots of things that we thought implicitly or explicitly in the past quite reasonably ought to count as evidentially informing our acceptance or rejection of testimony in the present. And (2) even on the narrowest individuation of testimonial context, the acceptance of testimony by default is conditioned by theoretical knowledge or beliefs that serve to link evidence from our wider experience with the resulting BFT. That evidence should count as supporting reasons for belief. Moreover, (3) testimonial contexts are very often epistemically and socio-linguistically engineered in order to generate testimony that can rationally be accepted quickly and unreflectively. Reasons for engineering the contexts in these ways plausibly count as reasons that support accepting the testimony generated in those contexts. And finally, (4) engineered or not, even our immediate surroundings in a testimonial context express or encode a lot of information - in particular, far more information than is reflected in thinly-drawn SIO examples from the literature. Under analysis, many of the literature's purported examples of justified BFTs that are informationally impoverished turn out to be informationally very rich.

I won't offer a conjecture on how to quantify information in the relevant sense, nor on how much information is minimally sufficient to justify a belief. These are good questions for all epistemologists, of course, but for now I am satisfied to speak of information in the same general sense that a proponent of SIO speaks of it. It is enough to show that, in this sense, there is lots of information in the testimonial contexts offered in support of SIO - intuitively, enough information that it's implausible simply to assert that there isn't enough for BFTs to be evidentially justified in those contexts. And if we modify the SIO examples to make them more clearly informationally impoverished, we undermine the intuition that they would generate cases of justified BFT after all.

In fact the typically thin character of those examples has long been a real problem for this literature. Writers on all sides of the issues sketchily describe, or merely mention, cases of speakers testifying as to their home address, date of birth, what they had for breakfast, or the features of objects that are in plain view. ${ }^{4}$ The idea that such assertions are

${ }^{4}$ C.A.J. Coady, Testimony: A Philosophical Study, Oxford UP (1992), pp. 269-70; E. Fricker, 'Telling and Trusting: Reductionism and Anti-Reductionism in the Epistemology of Testimony', Mind, I04 (I995), pp. 393-4II, at p. 405; C. Insole, 'Seeing Off the Local Threat to Irreducible Knowledge by Testimony', The Philosophical Quarterly, $5^{\circ}$ (200o), pp. 44-56, at p. $5^{\circ}$. 
inherently and immediately credible might be plausible; but only reflection on the actual or likely features of specific contexts can tell us whether they are moreover genuine scarce-information cases. In defending the informational richness of testimonial contexts, I will also suggest a diagnosis of the trend of under-described examples offered in support of SIO. Informationally impoverished descriptions of BFT formation are apt to lead us to attribute a scarcity of information to BFT-fixation contexts themselves. These descriptions predictably mislead us about the informational richness of testimonial situations, I suggest, because they activate a cooperative communicative principle on which we implicitly presuppose whatever factors would have to obtain in order for the example's communication to succeed as described.

I will begin, however, with a brief summary of the significance of SIO in the epistemology of testimony. The worry about justified BFT arising from contexts of scarce evidence has influenced writers on all sides of the field's most-discussed divide, and my project in this paper has some clear antecedents in the literature as a result.

\section{STAGE-SETTING: POSITIONS ON TESTIMONY}

The reductionism to which Lackey alludes in the opening quote is testimonial reductionism: roughly, the view that testimonial knowledge or justification is merely the aggregate of knowledge or justification based on more general evidential grounds. ${ }^{5}$ Reductionism is most often contrasted with credulism, or testimonial fundamentalism, the view that justification or knowledge gathered through assertion is irreducible, comprising a (defeasible) standing epistemic license to accept a piece of testimony merely on the grounds that it has been asserted. ${ }^{6}$ The license in question is sometimes depicted as a 'default justification' for accepting all testimony, ${ }^{7}$ and sometimes, as by Christopher Insole, in terms of (PR), a presumptive right to believe.

${ }^{5}$ E. Fricker, 'Against Gullibility', in B.K. Matilal, \& A. Chakrabarti (eds.), Knowing From Words (Dordrecht: Kluwer, I994), pp. I25-6I; E. Fricker, 'Telling and Trusting: Reductionism and Anti-Reductionism in the Epistemology of Testimony', Mind, I04 (I995), pp. 3934II; T. Shogenji, 'A Defense of Reductionism About Testimonial Justification', Noûs, $4^{\mathrm{O}}$ (2006), pp. 33I-46.

${ }^{6}$ C.A.J. Coady, Testimony: A Philosophical Study, Oxford UP (1992); L. Stevenson, 'Why Believe What People Say?', Synthese, 94 (1993), pp. 429-5I.

7 See, for example, M. Weiner, 'Accepting Testimony', The Philosophical Quarterly, 53 (2003), pp. 256-64, at p. 257. 
(PR) 'A hearer has the epistemic right to believe testimony merely on the grounds that it has been asserted'. ${ }^{\text {. }}$

The right to which PR alludes is of course meant to be a defeasible one; it is only a prima facie or pro tanto license to accept testimony. Countervailing evidential considerations can outweigh or defeat PR in specific cases. But in the first instance, absent any other information, fundamentalism regards BFT acceptance as warranted by default.

Testimonial fundamentalists (and anti-reductionists more generally) have taken examples like Lackey's to be a problem for reductionism. For that matter, SIO has been regarded even by reductionists as a significant objection to global reductionism, the thesis that all of one's known or justified BFTs, however remote and obscure their provenance in one's personal history, can or ought to be reduced to knowledge or justification in terms of perception, memory, and reason. Global reductionism has also been taken to founder on a range of other problems, including those of testimonial influences on perceptual knowledge itself, and of seemingly justified beliefs acquired through testimony in one's childhood, when one's inductive reasoning powers (at least) are both too unformed and too illinformed to plausibly play the appropriate justificatory role. Indeed, SIO has more or less the same shape as the objection from childhood BFT: both objections purport to present a class of cases of intuitively justified BFT, for which no reductionist evidential justification seems available. This suggests that at least some testimonial justification is non-reductionist. Considerations of explanatory virtue then speak in favour of regarding this non-reductionist justification as an entirely general prima facie justification for accepting testimony. Reduction-friendly justificatory factors, where available, are depicted as contributing only to the ultima facie justification of BFT, either by defeating the general non-reductionist justification or by providing independent reinforcement of it.

In response to objections to global reductionism, Fricker proposes the refinement of local reductionism. On this view we ought to bracket worries about childhood beliefs, the theory-ladenness of perception, language acquisition cases, and the like. We focus instead on particular instances of testimonial acceptance among basically competent adults. Rather than assessing whether all testimony can be reduced, we ask whether, for a

${ }^{8}$ C. Insole, 'Seeing Off the Local Threat to Irreducible Knowledge by Testimony', The Philosophical Quarterly, 50 (2000), pp. 44-56, at p. 46. Insole's wording loosely follows that of Fricker in 'Telling and Trusting', who coins this term to stand for the thesis that 'there is... a presumptive right to believe in what one is told just as such (but defeated by evidence of the speaker's insincerity or error)' (p. 399), and who considers a slightly different formulation of Insole's argument for this conclusion ('Against Gullibility', p. I27). 
given instance, 'the hearer has evidence that particular speaker in question is to be trusted with respect to her current utterance'. ${ }^{9}$

Does SIO apply also to the local version of reductionism? Prima facie, yes. Lackey does not distinguish global from local reductionism when presenting her counterexamples of accepting New York travel directions and assertions made in British newspapers. As we will see, examples in the literature contrast the sparse information hearers generally possess about strangers with the allegedly great general trustworthiness accruing even to strangers when they report such specific mundane things as their own names, telephone numbers, addresses, dates of birth, and so forth. Because these examples are themselves local cases or one-offs, they seem to apply to local reductionism too. ${ }^{\text {IO }}$

So on the fundamentalist side of things, it's a familiar allegation that there is a scarcity of information to justify accepting testimony in a wide class of cases - sometimes framed as the contextual inability to gather the necessary information. 'It is not in fact possible generally for the hearer to obtain independent confirmation that a given speaker is trustworthy', as Christopher Insole puts it. ${ }^{\text {II }}$

Lackey's endorsement of SIO, by contrast, is not in the service of fundamentalism - in fact she carefully discusses the respects in which relevant information can function as reasons justifying BFT even in default acceptance contexts. To this extent, Lackey and I are pulling in the same direction. She takes SIO to undermine reductionism because she takes reductionism to be committed to a higher bar for justification (in context) than her own hybrid dualist view of testimony proposes. ${ }^{\text {I2 }}$ The idea is that there is enough information to evidentially justify default BFT by dualist standards, but not by reductionist standards. Moreover, as we will see, Lackey holds that at least Fricker's reductionism can't appeal to the available information in any event. Still, the interesting thing is not so much that fundamentalists and hybrid non-reductionists take SIO to be a problem for reductionism. It's that even local reductionism is apt to treat SIO as a problem that forces a major exception onto the view. The exception

9 'Against Gullibility', p. I33.

${ }^{10}$ Lackey cites similar objections from M. Webb, 'Why I Know About as Much as You: A Reply to Hardwig', The Fournal of Philosophy, go (I993), pp. 26o-7o, at p.263; L. BonJour, Epistemology: Classic Problems and Contemporary Responses, (Lanham MD: Rowman and Littlefield, 2002), p.I72; and R. Foley, 'Egoism in Epistemology', in F. Schmitt (ed.), Socializing Epistemology: The Social Dimensions of Knoweledge (Lanham MD: Rowman and Littlefield, I994), pp. 53-73, at pp. 57-8.

II 'Seeing Off the Local Threat', p. 46; see also Coady's Testimony, p. 82.

${ }^{12}$ Learning From Words, pp. ${ }_{176} 65$. 
is a class of contexts in which there is presumptive right to accept testimony after all.

At any rate, this is what Fricker seems to defend. In 'Telling and Trusting,' she writes:

I find my own intuitions about testimony wildly volatile: consider some cases, and it seems obvious that we must have a default position of trust in what others tell us - that human personal relations would be unimaginable without this; but consider others, and it seems equally obvious that our attitude to others must be critical and skeptical, that we must and do weigh the balance of probabilities against what they say being true, on the one hand, and against their being mistaken or insincere on the other (p. 406).

Fricker's response to this split of epistemic intuitions is to disaggregate: to split the category of testimony into sub-kinds that are epistemically distinct. So in a given context we either adopt 'a default position of trust in what others tell us,' or we assess the truth of what they say on the basis of evidence that informs 'the balance of probabilities' (p. 407).

The key question about this implicit dichotomy is whether the fact that 'some people or types of people on some topics are reliable, others on others aren't' is properly understood in terms of 'whether and when we may rightly trust without evidence' (p. 407; my italics). Fricker introduces the label mundane testimony for the seemingly clearest cases of this phenomenon. Mundane topics are those about which a speaker could hardly be mistaken, such as 'her name, where she lives, what she had for breakfast, what is in clear view in front of her, and so forth' (p. 405). The upshot is that assertions about garden-variety matters of personal expertise are open to non-evidential justified acceptance. So even local reductionism leans toward the view that justified BFT, or a significant element of it, is so evidentially impoverished that it should be treated as justified by default, without evidence.

To defenders of the presumptive right thesis like Weiner and Insole this seems a massive concession. Fundamentalism takes our (primary) justification for BFT generally to be non-evidential. So non-evidentialism regarding mundane testimony looks like a clear instance of PR, the presumptive right thesis. Thus Weiner (p. 262), in spelling out his anti-reductionism, endorses Fricker's Acceptance Principle for Mundane Testimony: 'We are justified in accepting something that we are told concerning a mundane topic unless there is positive evidence against doing so.' And Insole (p. 5o) also follows Fricker in postulating a 'default setting for sincerity and competence' with respect to 'unknown informants' assertions concerning their own name, address, place of birth, and age,' as well as assertions about the directions to local destinations. 
Now, it is not clear (to me, at least) how deeply attached Fricker really is to this non-evidentialist spin on disaggregation. Elsewhere in the same paper she argues that local reductionism requires that 'I have adequate grounds to take my informant to be trustworthy on this occasion independently of accepting as true her very utterance' (p. 404, my italics). Here Fricker treats adequate grounds as more or less comprising grounds to regard the speaker as sincere and competent. Even were this approach wrong regarding testimony, it is at least clearly evidential in character. ${ }^{13}$ Similarly, Fricker holds that 'a normally knowledgeable adult will be absolutely awash with relevant circumstantial evidence bearing on the question of whether the speaker is to be trusted on her topic'. ${ }^{14}$ Notwithstanding some exegetical questions about the scope of the phrase 'on her topic,' this strikes me as consonant with my understanding of the informational richness of testimonial contexts, and with Lackey's own account of how information in a testimonial context can defeat SIO. Yet Lackey holds that Fricker can't appeal to the justificatory relevance of all this information for mundane testimony - because, according to Fricker's presumed non-evidentialism regarding mundane testimony, this information is inessential to mundane justification.

I will not defend a view on whether Fricker is getting a bad rap; whether her view is internally inconsistent; whether Lackey's hybrid view really is distinct from reductionism; or any other similar interpretive matter. Nor am I offering my arguments as an unconditional defence of reductionism. Indeed, the foregoing remarks are meant to explain (in part) why I think it's unclear what the commitments of reductionism are. But I need neither adopt nor reject those commitments in order to argue that there is a great deal of evidence available to justify BFT even in the contexts that SIO cases, and related examples, depict as informationally impoverished. Fundamentalists, reductionists, and hybrid theorists might well agree in principle that plenty of information is typically available for BFT justification in testimonial contexts. Again, the role of SIO is to show that, because insufficient information is available in some contexts that nevertheless generate justified BFTs through default acceptance, we should conclude that evidence or information is not required for BFT justification - not even in the cases where that information is available.

In part by extending and providing detail to arguments offered by both Lackey and Fricker, I will contend that SIO does not in fact show this.

\footnotetext{
${ }^{\text {I3 }}$ It would be mistaken if, for instance, sincerity were inessential to justified acceptance, as Lackey's (pp. 48ff) 'Creationist Teacher' example suggests.

${ }^{\mathrm{I} 4}$ E. Fricker, 'Trusting Others in the Sciences: A Priori or Empirical Warrant?', Studies In History and Philosophy of Science Part A, 33 (2002), pp. 373-83, at pp. 380-I.
} 
The examples offered as cases of justified BFTs arising from contexts of insufficient information are implausible. Taking their details seriously reveals that such situations are in fact informationally very rich; the persuasiveness of the examples depends on the lack of detail in which they are drawn.

\section{INFORMATION IN TESTIMONIAL GONTEXTS}

The default acceptance of testimony is substantially more complicated than is usually acknowledged in the discussions and examples of it scattered throughout the epistemological literature. This is not because contributors to the literature are entirely silent regarding the complex language pragmatics and psychology of default testimonial belief fixation, but because often the relevant details are not brought to bear or given sufficient weight when examples are formulated and considered. On one hand, for example, Robert Audi helpfully addresses some contextual and psychological factors attendant on default BFT fixation. ${ }^{{ }^{5}}$ On the other hand, I doubt that asking someone the time of day is ever as straightforward as Audi suggests when explaining his view that BFT is noninferential: 'I ask you the time; you tell me it is nine o'clock; and straightaway I believe this on the basis of your saying it'. ${ }^{16}$ In fact I think this is oversimplified in every particular. There is excellent reason to think that I don't just ask, you don't just tell me, I don't just believe you, and if this all really did happen 'straightaway', there should at least be serious questions about whether I would be justified in my acceptance. Even mundane cases of justified BFT formation are apt to implicate a great deal of information and information-processing. I will discuss four main respects in which this fact may be under-appreciated.

\section{III.I. Individuating testimonial contexts}

As a younger man, I occasionally earned money by playing (something like) music in a band. Some friends at the time never seemed to get over the idea that my band could play a gig for two hours and get paid, say, a thousand dollars. Four band members to split the money; that's a hundred and twenty-five dollars an hour!

${ }^{15}$ R. Audi, Epistemology: A Contemporary Introduction to the Theory of Knowledge, 2nd ed. (Routledge: New York, 2003), p. I35.

${ }_{16} 6$ 'Testimony, Credulity and Veracity', p. 26. 
It sounds too good to be true, and it was. Each of those hours of performance represented at least a dozen hours of group rehearsal, and each group rehearsal represented many hours of private rehearsal. Each gig and rehearsal involved hours of packing, driving, and unpacking musical gear. Of course it looked like a means of fast and easy money if all one focused on was the moment of performance. But it turns out that the remunerative properties of musicianship are not correctly assessed by focussing only on the occasion of performance. If one really wants to know whether music is easy money, one must take into account many relevant events that happen well before the paid performance.

The point is not unique to the economics of live performance. Imagine a situation in which every member of a voting body except for one has cast ballots on a motion, at which point there is a power outage that forces everyone to leave the voting chamber. It turns out (though nobody need know it at this point) that the cast ballots add up to a tie vote. So when the session reconvenes, the power to decide the question lies in the hands of the one person who has yet to vote. The instant her single vote is cast, the motion passes or fails. Is this situation therefore undemocratic?

The answer, I take it, is quite obviously No. Normally we might think that a situation in which one person has the power instantly to decide an issue seems undemocratic; but, again, that's just a bad way of individuating the situation. Everyone else has already cast a vote, and it was precisely this prior and extended exercise of their power to vote that created the momentary situation in which the single remaining voter's ballot would be suddenly decisive. That the other ballots were cast earlier does not demote their role in determining the outcome. It would even be unilluminating to think of those earlier ballots as being relevant but diminished - as if they were, say, 'background votes'. With respect to determining the outcome, they are all just ballots. The fact that one person ends up with the sole power to decide the matter when the situation is individuated narrowly doesn't mean the situation is undemocratic; it means that individuating the context that narrowly is a mistake.

Now suppose we grant for the sake of argument that there are narrow individuations of testimonial contexts on which a justified BFT is formed even though little evidence for that belief is accessible or processed in that context. There are at least two interpretations of this: either those are the right individuations of the testimonial context, and we need an epistemology of testimony that accommodates SIO; or those are overly narrow individuations of the context, and we should consider widening the context to include evidential reasoning performed earlier that might serve to ground reasons for the BFT. When pressing the SIO, it seems to 
me, the standard approach in the literature is the former. This is unwarranted. Reflection on both the remunerative properties of musical performances and the democratic properties of breaking a tie vote suggest that it's just plain wrong to take such a line on the epistemic properties of BFT.

Beliefs, experience, theoretical knowledge, and evidence or information more generally stand to BFT justification as rehearsal stands to the remunerativity of performance art, and as already-cast votes stand to the democratic properties of a final voter's determining the outcome of a tie vote. It's easy to think that one is getting more justification out of BFT than merely evidential reasoning about the testimony would warrant, if we focus on the contrast between the information cognised then and there and the epistemic payoff derived then and there by the adoption of the belief. But past reasoning is apt to be, not just relevant to, but partially constitutive of the justification of one's BFT in the immediate event.

It is a nearly universal view that settled beliefs and past reasoning are relevant to BFT justification, but this is consistent with supposing that these states and processes play a fundamentally different role from cognition that takes place at the point of belief fixation. Background beliefs are frequently assigned a distinctive structural role, or one of mere filtering for credibility, for example. ${ }^{17}$ I propose that, just as votes cast earlier are democratic votes, period, and not 'background votes', so too is our earlier reasoning (explicit or implicit) apt to serve as justifying reasoning, period. At least the burden is on the defender of SIO to show that we should not spatio-temporally individuate contexts of justified BFT acquisition in order to include factors that would straightforwardly apply to justifying the acquisition of the BFT. I see no promising independent grounds for taking such a view. The limits on such individuation might reflect one's commitments to (various types of) internalism or externalism, of course, but even internalists will for the most part have considerable freedom to carve a wide temporal swathe in identifying the constituents of a BFT's justification.

The upshot is a more forceful conception of the significance for BFT justification of relevant information from one's wider experiential and cognitive history. Still, to say this much is not yet to suggest what counts as information apt to ground reasons that justify BFT, in the sense to which Lackey alludes in presenting SIO. It is a related but distinct question how our local dispositions to accept testimony by default may themselves simply express or reflect experiences, beliefs, or theoretical

${ }^{17}$ Audi, Epistemology, p. I34.

(C) 2012 The Author The Philospohical Quarterly $\mathcal{C} 2012$ The Editors of The Philosphical Quarterly 
commitments that mediate between a rich stock of evidence, on one hand, and BFT on the other.

\section{III.2. BFT justification and experientially informed theoretic beliefs}

A wide range of expectations, beliefs, and experiences should be regarded as playing an immediate constitutive role in grounding the justification of BFT. Furthermore, though, the formation and justification of BFT implicates standing cognitive and information states that relate past information-processing to current BFTs. We can think of these states as our theories and models of how the world works.

One of the most fruitful approaches in this aspect of the literature is Fricker's appeal to a commonsense person-theory. ${ }^{{ }^{8}}$ I will take this to be a typically implicit set of beliefs or other psychological structures regarding the kinds of things that people tend to say and do, and the reasons for which they tend to do these things. On reflection it seems clear that we have such a theory, and that it has as much claim to be called a theory as does our 'theory of mind', which it probably includes as a proper part. For my purposes there are two key features to note about such a theory of persons, as I will call it.

First, it is deeply informed by information from experience. My experiences of other people, and my accumulated information about their interests, dispositions, ways of life, social aggregations, and so forth, plausibly figure strongly in my theory of persons. For example, I have the empirically informed concept of a kind lie (or white lie). I also have the empirically informed belief that most people around me think of some lies as kind lies. And I have a rough and ready empirically informed sense of the types of pairing between utterance contents and utterance contexts that might be considered kind lies. The activation of these sociolinguistic concepts and beliefs affects my dispositions to accept a piece of testimony in many situations, bringing all that information to bear on my acquisition of many BFTs.

Indeed, that is the second point: theoretical knowledge of this sort enables fast one-off predictions, explanations, and evaluations of the speech and actions of people I encounter. Through my theory of persons, my experiences partially shape the way I predict and explain practically everything I encounter involving persons. This includes shaping the judgements I make about their testimonial credibility, relative to a context and content of utterance. My theory of persons encodes my extensive

${ }^{18}$ 'Against Gullibility', pp. I48ff.

(C) 2012 The Author The Philosophical Quarterly (C) 2012 The Editors of The Philosophical Quarterly 
experience with people, and it is partially manifest in my ability to make evidentially-informed credibility judgements without explicit ratiocination.

A well-written and well-acted exchange between U.S. Treasury agent Elliot Ness and policeman James Malone in Brian de Palma's film The Untouchables nicely illustrates the role of a theory of persons, as I envision it.

Ness: 'You just turned your back on an armed man!'

Malone: 'You're a Treasury officer.'

Ness: 'How do you know that? I just told you that.'

Malone: 'Who would claim to be that who was not?'

Malone's method of reasoning here seems quite canny; but there is little temptation to suppose that he must have explicitly, consciously, performed it in first taking Ness's word at face value. This looks like no less a default judgement for the fact that it is mediated by a theory of persons, thereby implicating a great deal of information accessed and categorised, and having various effects on the agent's cognitive economy, well in advance of the encounter.

In fact the example (fictional, so caveat lector!) shows how the idea of a theory of persons can be extended or complemented. A key part of Malone's information concerns the position of Treasury officer, and the prominence and role of that position in the cognitive and social order especially in the cognitive and social order of a prospective criminal. This line of thought meets up with other examples, like Lackey's creationist biology teacher, whose students are intuitively justified in believing her (correct) teaching of evolutionary theory in spite of her insincerity (and, arguably, her incompetence) on the topic. In very different ways, the two cases exploit what we could call a theory of institutions; or maybe they exploit two different specific theories of institutions. Either way we can see a wide variety of theoretical apparatus that can be implicitly learned, consolidated, tested, and refined by experience over the longer term.

Another example from film, this one perhaps more accurately based on real-life events, is the criminal career of Frank Abagnale, Jr., whose early life as a forger and imposter was dramatised in the book Catch Me If You Can, and in the film of the same name. ${ }^{19}$ Abagnale claims to have successfully passed himself off for substantial lengths of time as a medical doctor, a lawyer, an airline pilot, and a sociology instructor at Brigham Young University, largely by exploiting just the sort of reasoning heuristic employed by De Palma's Officer Malone. Who would claim to be that, who was not? Wearing the clothes, employing some of the lingo, and 1980).

${ }^{19}$ F. Abagnale and S. Redding, Catch Me If You Can (New York: Grosset \& Dunlap, 
behaving in contextually appropriate ways imparted credibility to Abagnale's utterances in context. It did so for reasons that were obviously informed by his hearers' experiences and empirical theories of persons and theories of institutions.

Our theoretical beliefs include powerful evidential slingshots, like epistemic deference to experts, and the division of linguistic labour, through which we are variously informed about a wide range of topics. This is part of a more general person-theoretic and institution-theoretic capacity to recognise pairings of contexts and speakers as credibility-enhancing, as Lackey (p. I82) also observes. Similar remarks apply to more general social conventions or social epistemic principles. For example, Sanford Goldberg notes the epistemic leverage provided by the heuristic Don't accept an assertion for which it is highly probable that, were it true, you would already have heard about its reasonable claim. ${ }^{20}$ Plausibly, this is an evidentially virtuous principle in many circumstances. But one's coming to use it to real epistemic advantage is clearly based on information about one's community, one's epistemic position within that community, and the propensity for true claims of the relevant sort to percolate through (relevant portions of) that community on a particular timeline. Of course, one might also reason badly according to such a principle; but then, we frequently do err in accepting testimony automatically. The relevant point is that such a heuristic is conditioned by experience; that it comprises an ongoing influence on our default attitudes towards testimony of particular kinds, in particular contexts; and that it is clearly a reason to be offered in support of one's acceptance or rejection of a given piece of testimony.

All such ways of arranging and exploiting information via implicit and explicit theories contribute to defusing two influential characterisations of the prospect of generally evidence-based acceptance of testimony. These are, first, that the information would have to be sought out via deliberate legwork; and secondly, that the information primarily would have to be specific to the speaker in question. Thus, Coady (p. 82) finds it 'absurdly false to suggest that, individually, we have done anything like the amount of field-work' that a (specifically Humean) reductive thesis about testimony would require. Lackey (p. I8o) wonders how one could informationally justify one's acceptance of directions from a stranger given the impossibility of getting 'enough information about her' in the event (my italics). And Insole (p. 46) holds that it is impossible generally 'for the hearer to obtain independent confirmation that a given speaker is trustworthy' (my italics).

\footnotetext{
${ }^{20}$ S. Goldberg, 'If That Were True I Would Have Heard about it by Now', in A. Goldman and D. Whitcomb (eds.), Social Epistemology (Oxford UP, 201 I). pp. 92-108. 
Whatever the quality of these objections to the particular kinds of reductionism at which they are aimed, they do not apply to the mere observation that much general person-theoretic information can be, and plausibly is, in play when seemingly rapid BFT fixation occurs. Lackey too makes this point (p. I82), though she seems to hold either that reductionism cannot avail itself of such evidential resources, or that this evidence is too weak for reductionist purposes.

Taking the power and ubiquity of such information into account, I find it deeply implausible to view, for example, Officer Malone's justification for believing Agent Ness, such as it is, as having a non-evidential character, even though the two are, in the industry-standard sense, strangers. Nor does Malone's lack of experience with Ness in particular, or with Treasury officers more generally, support the thought that his contextual evidence is therefore too sparse for his (arguendo) justified BFT to be based on anything but a presumptive epistemic right to accept testimony.

\section{III.3. Engineering testimonial contexts in the world and in the mind}

At this point, it might seem worth asking why philosophers have found it so tempting to see BFT fixation contexts, especially the default acceptance ones, as having the low-information character that motivates SIO. There are two main components to the explanation, as I see it, bearing on both real and imaginary cases of BFT acquisition.

Whenever we communicate with one another, we implicitly exercise principles of interpretive charity to recover sensible - and, if possible, credible - assertions in light of the context. That's just part of being a competent and cooperative language-user, as theorists in language pragmatics have long emphasised: given a context and an utterance, a cooperative audience interpretively generates an asserted content.

What happens when we encounter philosophical examples like the two briefly sketched by Lackey in the opening quote? When we are provided with such thin or schematic examples of testimonial exchange, I suggest, a similar charitable process takes place. That is, supplied instead with (ex hypothesi) a justifiedly believed asserted content, we seem to be equally accomplished at the complementary process of implicitly constructing or presupposing a context of communication that would bear out the credibility of the assertion.

When we imagine a context in which we are justified in believing someone's report of their home address or what they had for breakfast, we might find ourselves automatically thinking of a legal witness stand, or a visit to the doctor, or just a conversation of reasonably warranted trust 
under socio-conventional features appropriate to making that very report credible. Indeed, we might think of nothing in particular, yet more or less mentally stipulate that whatever properties are necessary to the testimony's success are in place in the scenario. There is something default going on, in this sort of interpretation, but it's not the default justification of the assertion-type described in the example. It's our own tendency to default to a cooperatively rationalised scenario when considering the example.

As an exercise, I would ask you to imagine a case of justified BFT arising from straightforward, mundane testimony that takes place outdoors. Really - right now, before going any further, please take some time to think of a scenario in which some credible and simple piece of testimony is presented outdoors.

Now, can you report how loud the wind was, in the scenario you imagined? I take it that you imagined a scenario on which the wind noise played no role whatever. And why shouldn't you have done so, after all? Wind noise in the imagined scenario could only have been irrelevant, or, if it were loud enough, an impediment to the communication. But I didn't ask you to imagine a scenario with additional irrelevant details, and I certainly didn't ask you to imagine a failed case of BFT formation. So, being an efficient and cooperative audience, you factored out the wind altogether. Of course that doesn't show that testimony takes place airlessly, nor that the air that is present in testimonial contexts is motionless.

Now think again of Audi's example: 'I ask you the time; you tell me it is nine o'clock; and straightaway I believe this on the basis of your saying it.' Prima facie this is straightforward and plausible. But am I even wearing a watch when Audi asks me? Is there anything else about the situation suggesting that I might have a better idea than Audi himself as to the time? Do I answer Audi in a precise way, and instantly - '9:I7!' - in spite of not wearing a watch, and without breaking eye contact to consult any other time-keeping device? And does Audi straightaway believe me in these circumstances? These eventualities are trimmed out of consideration by the reader when the example is taken as an example. Maybe we fill in other details that would rationalise acceptance, or maybe we just stipulatively factor out evidential concerns altogether, in the spirit of reconstructing the example cooperatively. But this no more shows that the scenario would lack evidential (or inferential) reasoning than it shows that the scenario would lack air.

In short, I suggest that common SIO examples don't have their rhetorical power in spite of their lack of detail. They have rhetorical power because of their lack of detail. This tends to obscure, first, the informational richness of the situations in which believing the reports would be intui- 
tively justified, and secondly, the live possibility that believing the report in the situation as described, or on empirically plausible sharpenings of that description, would not be intuitively justified.

This cooperative interpretation of thinly detailed examples parallels the actual construction of communicative contexts in a key respect. To see this, we can reflect on how Audi's case might unfold in actuality. In particular, Audi himself is likely to trim away at least the initial worries mentioned above - i.e., is there any reason to think I'm likely to tell him the correct time? - just by deciding whether I'm a good person to ask about the time in the first place. We actually engineer testimonial situations in part with the aim of making the testimony credible, after all. Sometimes the engineering is at the grand socio-institutional scale (like building education systems with trained experts to staff them), in which case our theoretical knowledge of instititions comes into play. But we nearly always micro-engineer scenarios as well.

We craft questions to elicit answers in useful forms, and we time those questions, and direct them at particular interlocutors, in order to improve the credibility of the answers as well. In many circumstances this makes it reasonable to quickly accept answers falling in a distribution of expected answer-types, given the question and the context. When this works to generate justified BFT, though, it works because we crafted that context by mobilising just the sorts of evidence-based beliefs and dispositions already described as operative in default BFT fixation.

By analogy, we wouldn't say that I fail to exercise continence if I deliberately avoid situations containing some known temptation to bad behaviour. We should say I exercise my willpower precisely by exploiting my selfknowledge, and my beliefs about how the world works, in order to manipulate my environment and isolate myself from those temptations. Neither should we say that I fail to have an evidential basis for a BFT if I mobilise implicit or explicit evidential reasoning to construct a situation yielding up prima facie credible testimony, and then believe that testimony without much further thought. For example, when I stand in a crowded rail station, there are many people I could try asking, in order to find out which platform my train leaves from. I choose to ask a person wearing a rail company uniform, on the basis of a good deal of experiential and empirically-based theoretical information. If I then believe her answer without taking much further time or making much subsequent effort to reason about her credibility, my acceptance inherits the informational basis that motivated my engineering the context in that way. Whom I ask, what I ask them, how I ask it - all these things and more will shape a testimonial context in light of my antecedent beliefs, and in order to generate easily credible answers. 
The man who is clearly wearing no watch, the woman sitting absorbed in her book, the man leaning against the wall, smoking, with his hat pulled down quite low - it is practically certain that none of these people gets asked the time by Audi. These people represent real features of actual unsanitised situations, encountered when we are out doing applied testimonial epistemology by asking people stuff. Similarly, consider the examples of automatically and justifiedly trusting the directions one receives from a local when one is traveling. Do we really just ask the first person we see for directions? I can't believe that I'm unique in scanning even a crowded sidewalk, sometimes at length, looking for someone to ask for directions. I'm not even sure precisely what I'm looking for when I do this, but it seems clear that I'm looking for something in an interlocutor that will improve the odds of a credible report - that is, even in basically unthreatening circumstances, so that I'm not merely choosing an interlocutor in order to avoid a potentially dangerous encounter.

For a direction-finding example, think of being in a popular warmweather tourist destination, and needing directions to a small café you've heard about, located well off the main streets and said to be little-frequented by tourists. Of the various people you see on the street, presumably you would not ask directions of the badly sunburned man wearing the new-looking but ill-fitting t-shirt that features a weak, irrelevant pun and the name of that city printed on the front. That man's bad sunburn radiates information. His kitschy shirt is information, as is his expensive and spotless safari-style hat. He may be a stranger to you, in the ordinary sense of the term, but he is festooned with informational cues that comprise a rich testimonial context. You are likely to dismiss him from consideration as a person to ask, perhaps without even remembering that you did so. Again, the selection and avoidance of interlocutors when you ask a question implicates a great deal of information that is properly counted as evidence in one's possession for the purposes of assessing the epistemic status of the resulting BFT, however quickly and automatically it may be formed upon receipt of the answer.

Another example suggesting that BFT is justified in evidentially impoverished cases, this one from C.A.J. Coady, ends up being a very effective example of contextual engineering in action. Coady argues:

In our ordinary dealings with others we gather information without this concern for inferring the acceptability of communications from premisses about the honesty, reliability, probability, etc., of our communicants. I ring up the telephone company on being unable to locate my bill and am told by an anonymous voice that it comes to $\$ 165$ and is due on ${ }_{15}$ June. No thought of determining the veracity and 
reliability of the witness occurs to me nor, given that the total is within tolerable limits, does the balancing probabilities figure in my acceptance (I992, p. I43).

This demonstrates not just the power of epistemic situational engineering, but the ease with which its evidential leverage is overlooked. At first glance the example, like Audi's, focusses more on whether we use evidence than on whether it's altogether absent from the situation. But Coady's remark about not determining the veracity and reliability of the speaker is key: my response is that these facts have indeed already been substantially determined in the example as written.

Coady's conclusion might have followed from the example, were it a case of dialing a telephone number at random, and yet somehow coming away with the claimed justified BFT. But obviously that isn't what happens here. And if Coady had simply dialed a number at random - if he had asked whomever answered the phone how much he owed the phone company, been told 'I65 dollars,' and just believed it - surely we would not treat that as a touchstone case of justified BFT!

Rather, a vast amount of justificatory information is packed into the phrase, 'I ring up the telephone company.' Every reason Coady has for deliberately dialing the telephone company's number, confident that this is a way of contacting a person willing and able to report on his account balance, is a reason supporting the BFT acquired via the subsequent exchange. That the person who answers does not provide a name is practically irrelevant. Given the aim of the phone call, the name of the telephone company worker pales in evidential significance compared to the fact that they work at the telephone company.

\section{III.4. The informational richness of immediate context}

I have been arguing for the informational richness of testimonial contexts, broadly individuated. The final point in my cumulative case for this view is that BFT fixation is sensitive to a great deal of information encoded or immanent in testimonial contexts, individuated narrowly. Local situations are informationally rich in ways we don't have to consciously calculate in order for our judgements to be affected by them. This information plausibly serves to activate and implicate earlier thoughts, general beliefs, and implicit theoretical frameworks of the kinds already discussed. We have already seen the phenomenon at work, when reflecting on the sort of contextual cues that would prompt the engineering of testimonial situations. That is, the presence or absence of a visible watch comprises relevant information in the context of testimony regarding the time of day. 
As immediate testimonial situations unfold dynamically, moreover, they display information in ways that are clearly consilient or inconsilient with working hypotheses, implicit or otherwise, about the reasonableness of testimony in those contexts. ${ }^{21}$ Returning to Coady's case of the telephone bill, we may note that in such a situation I would know far more even than that the speaker works at the telephone company in some capacity or other, by the time I got to the point of accepting or failing to accept testimony about my current bill. Suppose I dialed $a$ telephone company number, and the call was answered, 'Repairs and emergency service,' on a noisy connection with the sound of heavy machinery in the background. I've called the telephone company, yes. But how does that conversation go?

Me: I'm calling about my account balance.

Voice: A Uh, yeah. Sorry, I can't help you. I'm out in the field replacing an underground line that was cut. How did you get this number? I have to go.

Me: I can't find my bill, though. Couldn't you just tell me what I owe?

Voice A: Uh, okay. You owe I65 dollars.

Obviously the last assertion in that exchange doesn't generate a justified corresponding BFT in me. Given what we know about the distribution of account information and mechanisms of information retrieval at large companies, the fact that the speaker doesn't yet know my name is of far greater evidential significance than is the anonymity of the telephone agent in Coady's example.

Contrast this sort of justification failure with a reasonable take on how an epistemically favourable conversation would go.

Voice A: Telephone Company, how may I direct your call?

Me: I'm calling about my account balance.

Voice A: One moment, please. Directing your call to Client Services and Accounts.

$<$ Excruciating music, followed by ringing $>$

Voice B: International Fees and Deputations, how may I help you?

Me: Hello? I'm calling about my account balance.

Voice B: No, you need Client Services and Accounts. One moment please.

$<$ Excruciating music, followed by ringing $>$

Voice C: Client Services and Accounts.

Me: Hi, I'm calling about my account balance.

Voice C: What is your name and address?

$<$ Personal and account-identifying details are volunteered at some length>

Voice C: Thank you. Your current balance is 165 dollars.

${ }^{21}$ Cf. Audi 2003, pp. 134-5.

(C) 2012 The Author The Philosophical Quarterly (C) 2012 The Editors of The Philosophical Quarterly 
Now that last utterance is a bit of testimony that I could justifiably believe without reflecting at greater length on its evidential support. But interactions of this sort encode not just the substantial information that is initially engineered into them; they contain contextual cues that let us effortlessly expand and improve upon our state of information. Given that I called the telephone company, I have reason to believe the testimony of Voices $\mathrm{A}$ and $\mathrm{B}$ to the effect that I'm being directed to the billing department of the telephone company. The fact that Voice $\mathrm{G}$ then volunteers that information powerfully confirms this working hypothesis. After that, the confirmed hypothesis that I'm talking to the billing department surely functions as a justification for my believing what they tell me about my bill. The things that are said in the immediate context, and the way they are said, interact with my theoretical knowledge dynamically in ways that generate a rich stock of reasons for rational belief.

We can generalise the point to many elements of testimonial situations: time of day, day of week, the speaker's clothes, shoes, smell, visible hygiene, speech accent, and manner of walking (e.g., confidently through university hallways, or tentatively, peering at office numbers as if lost or uncertain). Each of these elements is a dimension along which the evidential credibility of even a stranger's utterance can vary, especially in light of its content. Thus it seems perfectly clear that we are not discussing situations in which my subsequent rational entitlement to accept the speaker's testimony must be 'independent of my past experiences,' as Weiner (p. 257) characterises and defends the concept of a presumptive right to accept testimony by default.

Of course I am not claiming that these considerations flat-out disprove the presumptive right view. That view rests on a range of arguments, and not on SIO alone. But I do think this shows that the PR thesis is not persuasively argued on SIO grounds, whether by fundamentalists who advocate an entirely general PR thesis, or by pluralist reductionists who see testimony as reductive in some domains and fundamentalist in others.

\section{EXAMPLES OF TESTIMONY AND THE ROLE OF A PRESUMPTIVE RIGHT}

These conclusions shouldn't really be surprising, upon reflection. After all, there are big differences between reliably knowing something that seems mundane, like one's own telephone number, and reliably testifying as to one's telephone number in some hypothetically context-neutral way. 
I suspect that supporters of the default credibility of mundane testimony often neglect those differences when it comes to the construction and use of testimonial examples. Thus they may give short shrift to the prospect that only in socio-institutionally special circumstances do people very reliably report on such details - circumstances that are, as we have seen, implicitly assumed to hold when such examples are cited.

I do know mundane things like my home address and my birthday, usually, and I am pretty reliable at writing them out on a driver's license renewal form at the Ministry of Transportation office. I am not very trustworthy in reporting them if they are demanded for registration for a recreational internet discussion forum, however. Similarly, people are probably pretty good at knowing their own body weight. But my prediction is that they are more reliable at reporting it accurately to the technical staff atop a bungee-jumping tower than they are at reporting it on a dating website. For that matter it is tempting to conclude from the state of the literature that prominent philosophers are either inattentive to, are inexperienced with, or are astonishingly successful at the phenomenon of asking for someone's phone number in, say, a nightclub. Few people bearing that context in mind would immediately think of phone number recitals as incandescent cases of credible testimony. License bureaus, nightclubs, bungee platforms and dating websites are all just contexts. None of them is a default context in any sui generis or epistemically intrinsic sense. It might turn out that, for example, most actual cases of people being told a telephone bill amount occur under circumstances much like those in my last dialogue. In that event, reports of telephone bill amounts would be typically credible; but presumably it would be the typically rich information characteristic of those contexts that makes them so rather than credibility arising from the mundanity of the utterance content and some pro tanto trustworthiness of speakers.

As I noted at the outset, defenders of a presumptive right to accept testimony agree that empirical details of the testimonial situation can function as defeaters of the presumptive right. ${ }^{22}$ To this extent they can regard with equanimity the letter of Fricker's claims that 'a hearer should always engage in some assessment of the speaker for trustworthiness', and that 'the hearer must always be scrutinising the speaker for telltale signs of [sincerity's] absence, and she must be alert to the presence of such signs. ${ }^{, 3}$ Again, nothing I have said here positively rules out that the infor-

${ }^{22}$ See, for example, S. Goldberg and D. Henderson, 'Monitoring and Anti-Reductionism in the Epistemology of Testimony', Philosophy and Phenomenological Research, 72 (2006), pp. $600-17$.

23 'Against Gullibility', p. I45; 'Telling and Trusting', p. 405. 
mation available in contexts of BFT fixation merely functions in defeatermonitoring, or as ultima facie additional justification sitting atop a more basic presumptive or default justification. It just undermines the sense that SIO supports the need for such a standing antecedent license to accept testimony, based on the thought that intuitively justified BFT outstrips informationally rich BFT contexts.

Of course there are contexts in which we lack sufficient information to evidentially ground a BFT. There are also contexts in which we acquire an intuitively justified BFT. Only if some of these are the same contexts are we enjoined to conclude that our intuitive, uncontroversial justification to believe testimony outstrips evidential support to believe testimony. Even the allegedly clearest SIO examples do not show this, I have argued, because there is a great deal of information available to provide reasons that justify BFT in those examples; and when we reconceive the examples more thoroughly to remove this information, we end up losing any sense that the BFT would be justified. Therefore SIO examples, as usually described, are not reliable guides to the ascription of justificatory grounds for BFT. They leave out essential evidential details, and our interpretation of them tends implicit or explicitly to smuggle evidence back in or wrongly idealise it away.

Perhaps we don't need to spell out epistemological examples in exhaustive detail (though it might not hurt to try it occasionally). But we at least ought to be careful in accounting for the details we aren't providing when we draw conclusions from thin or schematic examples, or when we use such examples to illustrate particular views on the nature of testimony. ${ }^{24}$ As things stand, the anti-reductionist conclusions extracted from SIO are most plausibly an artefact of the lack of detail in the treatment of those examples. When we think about the situational and cognitive details attendant on contexts of intuitively justified BFTformation, claims about the scarcity of information in those contexts emerge as unpersuasive. ${ }^{25}$

\section{University of Waterloo}

${ }^{24}$ Though it isn't offered as an SIO example, consider Lackey's (pp. I68ff) proposed testimony case ALIEN, in which an 'individual's physical appearance enables Sam to identify her as an alien from another planet' at a fleeting glance. The subsequent argument hinges on the claim that 'Sam knows absolutely nothing about the alien in question.' Here too it seems to me that the lack of detail is playing a load-bearing role in the argument.

${ }^{25}$ For helpful comments, my thanks to David DeVidi, Sanford Goldberg, Rachel McKinnon, the participants in my 2012 seminar on testimony at the University of Waterloo, and two anonymous referees for this journal. This work was supported in part by Social Sciences and Research Council of Canada Grant 4II-20II-I737. 